\title{
ARE MORAL ERROR THEORISTS INTELLECTUALLY VICIOUS?
}

\author{
Stephen Ingram
}

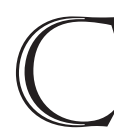

HARGING OTHER PEOPLE with intellectual vice is an important part of human life. One journalist might accuse another of being a narrow-minded conspiracy theorist, for example, or a lecturer might accuse her student of being intellectually lazy when he once again fails to do the required reading. We make "epistemic vice-charges," as Kidd calls them, for various reasons. ${ }^{1}$ Ideally, they can improve our dialectical situation by identifying, explaining, evaluating, and correcting bad epistemic activity. Less nobly, they can be used to stain a rival's reputation, or to make laypersons doubt an expert's testimony. Kidd distinguishes robust and rhetorical vice-charges. ${ }^{2}$ In rhetorical cases, one agent negatively evaluates another but cannot "elaborate or 'unpack' the charge ... by explaining the reasoning that supports the negative judgment." $\mathrm{A}$ rhetorical charge lacks epistemic force. Even if it is widely endorsed, without evidence to back it up it is indistinguishable from arbitrary name calling, and thus cannot advance a debate in an epistemically admissible way. But if a charge receives adequate evidential support it becomes robust, has real dialectical force, and can play a role in epistemic life.

Kyriacou suggests that we might need to issue an epistemic vice-charge against moral error theorists. ${ }^{4}$ He says this in response to an objection I make against the "moral fixed points view" defended by Cuneo and Shafer-Landau. ${ }^{5}$ This paper replies to Kyriacou. I show that there is little hope of making his vicecharge robust enough to vindicate the moral fixed points view. I begin with a brief overview of the debate. I then develop Kyriacou's charge, before arguing that it fails to vindicate the moral fixed points view.

1 Kidd, "Charging Others with Epistemic Vice."

2 Kidd, "Charging Others with Epistemic Vice," 183-84.

3 Kidd, "Charging Others with Epistemic Vice," 183.

4 Kyriacou, "Moral Fixed Points and Conceptual Deficiency: Reply to Ingram.”

5 Ingram, “The Moral Fixed Points”; Cuneo and Shafer-Landau, "The Moral Fixed Points." 


\section{BACKGROUND}

Cuneo and Shafer-Landau recommend that moral non-naturalists accept the following:

There are non-natural moral truths. These truths include the moral fixed points, which are a species of conceptual truth, as they are propositions that are true in virtue of the essences of their constituent concepts. ${ }^{6}$

A representative example of a moral fixed point (MFP) is the following:

A: It is wrong to engage in the recreational slaughter of a fellow person.

Cuneo and Shafer-Landau suggest that the essences of the concepts WRONG and RECREATIONAL SLAUGHTER OF A FELLOW PERSON are such that, when something satisfies the latter concept, it also satisfies the former.

I discuss putative attractions of this view below, but note first that it has the following entailment: anyone who denies an MFP is not just morally mistaken, but conceptually deficient. This includes error theorists, who hold that all of moral discourse is in error. Of course, to say that error theorists are conceptually deficient is not to say that they are metaethically flat-footed. Cuneo and Shafer-Landau make the subtler and more charitable claim that error theorists are misled as to what is implied by the content of their moral concepts. What misleads them, according to Cuneo and Shafer-Landau, is a suspect methodology. Specifically, one that involves "rejecting highly evident first-order moral propositions ... on the basis of either highly controversial metaethical claims, or speculative empirical claims."7 This supposedly underwrites the claim that error theorists are conceptually deficient. Not everyone is convinced, however. In earlier work I have argued that, when we examine the error theorist's method carefully, it is not clear what exactly is wrong with it. ${ }^{8}$

More specifically, I argued that the error theorist uses a standard philosophical methodology—roughly, a four-stage process of theory development:

(1) Get your intuitions in order. Scrutinise them, make them cohere, etc.

(2) Develop a theory that, if true, vindicates your intuitions. Test it against standard criteria. If it passes, accept the theory. If it fails, move to (3).

6 Cuneo and Shafer-Landau, "The Moral Fixed Points," 411-12.

7 Cuneo and Shafer-Landau, "The Moral Fixed Points," 438.

8 Ingram, "The Moral Fixed Points," 4. 
(3) Revise your theory. If it still fails after you have considered all available revisions, move to $(4)$.

(4) Accept that your intuitions were in error, and explain this error.

My suggestion was that error theorists operate in this familiar and apparently legitimate way. So, even if error theory is false, Cuneo and Shafer-Landau cannot ascribe conceptual deficiency to error theorists on the basis that they are misled by their method. Kyriacou, however, thinks that Cuneo and Shafer-Landau's view can be improved.

\section{KYRIACOU'S VICE-CHARGE}

Kyriacou proposes diagnosing the conceptual deficiency within a virtue-theoretic framework. The central idea is that virtues can dispose us to mastery of moral concepts, while vices can dispose us to conceptual deficiency. One way to develop this is to say that those who deny the MFPs do so because they are morally vicious. Their callous and sadistic character "induces some conceptual deficiency and moral blindness." ${ }^{\prime \prime}$ But that line of thought will not wash - the error theorists I know are lovely, not callous or sadistic at all. (Some of my best friends are error theorists!) For this sort of reason, Kyriacou suggests that error theorists do have an intuitive grasp of the MFPs when engaging in first-order moral thought. ${ }^{10}$ However, at the second-order metaethical level, they resist recognizing them as conceptual truths.

So, strictly speaking, error theorists should be accused of meta-conceptual deficiency. Kyriacou holds that, to support this, we should argue that error theorists are "not sufficiently virtuous in the relevant intellectual respects." ${ }^{11} \mathrm{He}$ submits that error theorists are blinded by "a stubborn and narrow-minded insistence on the suspect philosophical methodology of strong reductionist naturalism that values ontological parsimony over and above the value of saving the phenomena." 12 If this is right, it can underwrite the accusation of meta-conceptual deficiency. This would undercut my objection, vindicating the MFP view.

Kyriacou acknowledges that more work needs to be done to develop his suggested vice-charge. I do some of that work here, for it is necessary for the task of evaluating the prospects of making the charge robust. This matters, for if the charge remains rhetorical - that is, if it continues to lack adequate eviden-

9 Kyriacou, "Moral Fixed Points and Conceptual Deficiency," 4.

10 Kyriacou, "Moral Fixed Points and Conceptual Deficiency," 5.

11 Kyriacou, "Moral Fixed Points and Conceptual Deficiency," 5.

12 Kyriacou, "Moral Fixed Points and Conceptual Deficiency," 6, emphasis added. 
tial support - then it will possess no more epistemic force than arbitrary name calling. I focus on the charge of narrow-mindedness, for if error theorists are narrow-minded and stubborn then the latter is likely due to the former. I also read the charge charitably as targeting a "local" rather than a "global" vice. ${ }^{13}$ That is, instead of asking whether error theorists have a narrow-minded psychological profile in most or all (trait-relevant) contexts-something that would be very hard to establish-I instead evaluate the claim that they are narrow-minded in some relevantly localized range of contexts.

Indeed, what Kyriacou seems to have in mind are contexts relating to the methodology of "strong reductionist naturalism." So, let us say that the local vice-charge is that error theorists are narrow-minded-about-naturalism. This is what explains their meta-conceptual deficiency. To see what this amounts to, consider what is involved in narrow-mindedness for any given domain.

On one influential view, open-mindedness involves being motivated to be "receptive to new ideas and arguments even when they conflict with one's own in order to ultimately get knowledge." ${ }^{14}$ Being "receptive" to such ideas involves being willing and able to examine them without prejudice, without letting partisan commitments undercut conscientious inquiry. Correspondingly, then, narrow-mindedness involves failure or refusal to explore ideas or arguments that conflict with one's own, or else a prejudicial exploration of them.

It is worth introducing a nuance here. Philosophers often use "narrow-minded" and "dogmatic" interchangeably, and this reflects part of ordinary discourse. But we often reserve "dogmatic" for an extreme form of narrow-mindedness seen in those who are fanatically devoted to a doctrine-those who fail to receptively entertain rival ideas because they are in the grip of a worldview that seems unarguable to them. This fanaticism does not always apply to those we call narrow-minded. Those who find a view they like and fail to receptively entertain its rivals (where this is due to the fact that they already have a view they like) differ from those who are devoted to a worldview, and who are thus hostile to rival ideas, and attempt to repudiate them.

For example, consider (1) a fascist who feels a need to burn books that espouse rival ideas, and (2) someone who has no desire to view sources of news other than The Daily Mail because they like what they read there, but who also feels no deep loyalty to that paper and is indifferent to where others get their news. Both are narrow-minded, but in comparing them I am inclined to reserve the charge of "dogmatism" for (1). On this use of terms, which reflects part of ordinary language, dogmatism entails narrow-mindedness but not vice versa. In 
short, in some contexts we reserve "dogmatic" for those who are unusually dedicated to a worldview.

I note this because it forces us to ask whether error theorists should be charged with dogmatic narrow-mindedness. I have never met a book-burning error theorist-even if they turn out to be dogmatically-narrow-minded-about-naturalism, they will no doubt be at the milder end of the spectrum. But, whether or not they are dogmatic in this way, this is what the charge must be.

To see this, note that their alleged epistemic misconduct is radical. They are accused of meta-conceptual deficiency-reflectively resisting conceptual truths that they intuitively grasp. If this is underwritten by some form of narrow-mindedness, it is the dogmatic form to which we must appeal, for this is what it takes to explain why error theorists endorse a theory that conflicts with their own intuitions. In theorizing they fail to receptively entertain their own ideas. It plausibly takes a deep dedication to naturalism to produce such cognitive dissonance. So, the charge should be that error theorists are dogmatically-narrow-minded-about-naturalism. This is what explains the meta-conceptual deficiency involved in their denying the MFPS, and gives a way to defend Cuneo and Shafer-Landau against my earlier objection. With this charge on the table, we can now assess the prospects of making it robust rather than rhetorical. I suggest that the prospects are not good.

\section{A ROBUST CHARGE?}

\subsection{Intellectual Misconduct}

The first thing we have to do to get a robust charge is show that the intellectual misconduct that it is invoked to explain and evaluate really is intellectual misconduct. After all, if the error theorist does not misbehave, there is no reason to make the charge - no dialectical role for it to play.

Note that the misconduct here cannot just be that error theorists accept a theory that conflicts with their first-order intuitions. For if the theory is correct, and the intuitions in error, then this is the right thing to do. So, a robust charge will have to show that the putative MFPs really are MFPs, for if this can be reasonably rejected then it will be unclear that error theorists err in denying the MFPS, and thus that there is intellectual misconduct for the vice-charge to explain.

We must therefore assess the MFP view's plausibility. Cuneo and Shafer-Landau argue that it explains four facts about the claims that they have in mind as MFPs: (i) that such claims hold of necessity, (ii) that they fix the boundaries for what counts as a moral framework, (iii) that their denial incites bewilderment, 
and (iv) that they are knowable a priori. ${ }^{15}$ If this is right, then we have reason to call the MFPs conceptual truths, and there is intellectual misconduct to explain. But the MFP claim is not the only available take on (i)-(iv). Evers and Streumer argue that the essences of WRONG and RECREATIONAL SLAUGHTER OF A FELLOW PERSON do not make it a conceptual truth that

A: It is wrong to engage in the recreational slaughter of a fellow person. They suggest that it is only a conceptual truth that

B: If anything is wrong, it is wrong to engage in the recreational slaughter of a fellow person. ${ }^{16}$

Evers and Streumer note that this suggests a different way of interpreting (i)(iv). ${ }^{17}$ For instance, if their view is correct, it is only on the condition that $\mathrm{A}$ is true that it is necessarily true, or knowable a priori. And maybe Olson is right that error theory is emotionally difficult to accept-this may be what makes it so bewildering and disturbing when the MFPs are denied. ${ }^{18}$ We might also propose that $\mathrm{B}$ fixes the boundaries for what can count as a moral framework.

The idea that error theorists err in denying the putative MFPs (and that there is thus misconduct to explain) thus relies on the MFP explanation of (i)-(iv) being superior to this rival. We must settle the debate in favor of the MFP explanation before the charge can be seen as robust. However, to establish the superiority of the MFP explanation would effectively be to establish the MFP view, and whether this view is true is just what is at issue in this debate. So, one issue for defenders of the vice-charge is that they must find a dialectically appropriate way to establish the MFP view in order to show that there is some intellectual misconduct to explain.

\subsection{Cross-Situational Consistency}

Another, more troubling problem arises from the fact that we can ask whether error theorists have the psychological profile involved in being dogmatically-narrow-minded-about-naturalism. The best evidence we are likely to get here would be their acting similarly viciously in a suitable range of contexts, for this would indicate a characterological root from which the behavior springs. If error theorists are dogmatically-narrow-minded-about-naturalism, then it will be any context in which naturalism is at stake that is relevant. We can allow that error theorists

15 Cuneo and Shafer-Landau, "The Moral Fixed Points," 407-8.

16 Evers and Streumer, "Are the Moral Fixed Points Conceptual Truths?" 
might inquire virtuously when participating in a debate in which naturalism is not at stake, but the charge commits us to predicting that they are out to defend naturalism generally (or that, when they are forced to pick a side in a debate in which naturalism is at stake, they seek to defend it and repudiate its rivals). Thus, if the error theorist is dogmatically-narrow-minded-about-naturalism, we can expect them to have naturalistic views on the metaphysics of mind, mathematics, and logic, for they will fail to receptively entertain the idea that qualia, numbers, and identity (etc.) are non-natural. This is a localized prediction of "cross-situational consistency." How plausible is it?

It is true that some moral error theorists have been out to defend naturalism generally. Mackie considers whether numbers and identity (etc.) can fit into his naturalistic picture, and says that we must "show how, on empiricist foundations, we can construct an account of the ideas and beliefs and knowledge that we have of all these matters." ${ }^{\prime 9}$ Of cases for which he had yet to give his own empiricist theory, he says: "I can only state my belief that satisfactory accounts of most of these can be given in empirical terms," and that if any should "resist such treatment, then they too should be included, along with objective values, among the targets of the argument from queerness." ${ }^{20}$ Such remarks show little, however. They need not reflect failure to receptively entertain rival ideas, or some broader psychological profile.

And, besides, Mackie is just one man. The vice-charge targets error theorists as a group. Indeed, it has to do this in order to play the role that Kyriacou has in mind for it-namely, to vindicate the MFP view against my objection. I suggested that it is implausible that error theorists are conceptually deficient. Kyriacou replied that they plausibly are meta-conceptually deficient, at least once we explain how this came to be using a vice-charge. If the charge is to play this dialectical role alone, it must apply to all who participate in the relevant intellectual misconduct - to error theorists as a group. This is where issues emerge. There is no necessary connection between (a) the idea that non-natural moral truths are queer and (b) an overarching naturalistic worldview. ${ }^{21}$ That is, even if most actual error theorists endorse naturalism, nothing about error theory forces them to do so. We can imagine someone who finds irreducible normativity queer and thus believes that error theory is true, but who also thinks that qualia are irreducibly non-natural. Maybe nobody has defended this combination of views, but it is easy to imagine someone doing so. Nothing about error theory excludes this possibility. What might one say to explain the alleged meta-conceptual deficiency of this

Mackie, Ethics, 39.

Mackie, Ethics, 39. 
person? A new explanation is needed, for they are engaged in the same activity as other error theorists, but not because they are dogmatically-narrow-minded-about-naturalism. We can be certain of this, for they forsake naturalistic views of qualia. An obvious reply is to further localize the charge. Instead of saying that error theorists are dogmatically-narrow-minded-about-naturalism, perhaps we could say that they are dogmatically-narrow-minded-about-metaethics. Someone with this vice can inquire viciously on metaethical issues, like the MFPs, without this having any bearing on their inquiry about qualia and such. But this does not help, for we can imagine error theorists who inquire virtuously in metaethical debates that do not bear on their chosen form of error theory.

Consider someone who says that moral truths would have to be irreducibly normative, that irreducible normativity is queer, and that moral discourse is thus in error. This form of error theory is compatible with any view of moral motivation. Error theorists of this sort might inquire virtuously in debate over judgment internalism and externalism, for instance. So, the charge must localize further. And we can keep running this line until we reach the charge that error theorists are dogmatically-narrow-minded-about-moral-error-theory. But there are problems with such a narrow charge. First, it is uninformative. When the claim was that error theorists are dogmatically-narrow-minded-about-naturalism, we made interesting predictions about what they will do when their naturalistic worldview is at stake. We cannot say the same if the charge is that they are dogmatically-narrow-minded-about-moral-error-theory. The prediction in this case will be that the moral error theorist will defend moral error theory if it is at stake, and that, if she is shown an argument against moral error theory, she will seek to reject one of its premises. This prediction is uninteresting; it is what we expect of error theorists whether or not they are vicious.

Second, such a charge does not identify a vice. Local traits are one thing, but this charge is so narrow that the vice is not really an aspect of character. Doris does discuss hyper-local traits, but I agree with Cassam that "the sweet spot is somewhere between the mythical global traits which demand absolute consistency and ultra-fine-grained, situation-specific local traits which carry no implications for a person's conduct other than in a single case." ${ }^{22}$ The original charge plausibly does lie in the sweet spot but has limited dialectical force. The revised charge (that they are dogmatically-narrow-minded-about-moral-error-theory) is too localized to pick out a real character trait-something that could play a useful explanatory role.

A related issue with such a narrow charge is that it must be bolstered by a story of how the error theorist actually became dogmatically committed to error 22 Doris, Lack of Character, 66; Cassam, "Vice Epistemology," 174. 
theory. This is also true of the broader original charge, but getting a plausible story here is easy-for instance, we might say that error theorists are impressed (as many are) by the success of the natural sciences. But, having abandoned the original charge for the hyper-localized one, we must now ask how they came to this very specific vice-trait. And this is a harder task. Kyriacou suggests that the error theorist suffers from "theory-induced blindness." 23 This might explain why they have a hyper-localized vice of being dogmatically-narrow-minded-about-moral-error-theory. However, not everyone with a theory also has theory-induced blindness, so we need to explain why this afflicts error theorists in particular. Otherwise the debate will descend into "an interminable exchange of charge and countercharge," with error theorists accusing non-naturalists of having a theory-induced blindness that has led them to become dogmatically-narrow-minded-about-non-naturalism. ${ }^{24}$ Maybe it is doable, but it is a high hurdle to jump.

It is worth emphasizing that, even if the original charge were to succeed for every actual error theorist, the issue raised here still emerges. The point of Kyriacou's vice-charge was to explain the error theorist's alleged intellectual misconduct. If such misconduct can in principle occur without this vice, as it evidently can, then some other explanation-whether a narrower vice-charge or something else entirely - will be needed to supplement or refine the original charge.

\section{CONCLUSION}

I do not wish to rule out the possibility that such explanations could be given, but they would have to survive the sort of reasoning outlined above, at least if we wish to make the charge in question robust enough for it to be able to vindicate the MFP view. There are major difficulties with identifying a relevant vice-charge that can (a) be made robust and (b) play the dialectical role needed to support the MFP view. So, without a robust charge the MFP view remains in trouble, for its prima facie implausible commitment-that error theorists are conceptually (or meta-conceptually) deficient-has yet to be made plausible. Until plausible diagnoses of this intellectual misconduct can be given, we must reject this commitment, and the MFP view with it. ${ }^{25}$

University of Manchester stephen.ingram@manchester.ac.uk

Cf. Kahneman, Thinking, Fast and Slow.

Kidd, “Charging Others with Epistemic Vice," 184.

For comments on earlier drafts, I am grateful to Jimmy Lenman and Ian Kidd. I am also grateful to Lizzy Kirkham, Denise Fox, and Shirley Carter. 


\section{REFERENCES}

Cassam, Quassim. "Vice Epistemology." The Monist 99, no. 2 (April 2016): 15980.

Cuneo, Terence, and Russ Shafer-Landau. "The Moral Fixed Points: New Directions for Moral Nonnaturalism." Philosophical Studies 171, no. 3 (December 2014): 399-443.

Doris, John M. Lack of Character: Personality and Moral Behaviour. Cambridge: Cambridge University Press, 2002.

Evers, Daan, and Bart Streumer. "Are the Moral Fixed Points Conceptual Truths?" Journal of Ethics and Social Philosophy (March 2016).

Ingram, Stephen. "The Moral Fixed Points: Reply to Cuneo and Shafer-Landau." Journal of Ethics and Social Philosophy (February 2015).

Kahneman, Daniel. Thinking, Fast and Slow. New York: Farrar, Straus, and Giroux, 2011.

Kidd, Ian James. "Charging Others with Epistemic Vice." The Monist 99, no. 2 (April 2016) 181-97.

Kyriacou, Christos. "Moral Fixed Points and Conceptual Deficiency: Reply to Ingram." Journal of Ethics and Social Philosophy (March 2017).

Mackie, J. L. Ethics: Inventing Right and Wrong. London: Penguin, 1977.

Olson, Jonas. Moral Error Theory: History, Critique, Defence. Oxford: Oxford University Press, 2014.

Zagzebski, Linda T. Virtues of the Mind: An Inquiry into the Nature of Virtue and the Ethical Foundations of Knowledge. New York: Cambridge University Press, 1996. 